\title{
Sampling, Dilution, and Loading Device-coupled High- Performance Liquid Chromatography Method for Successive On-line Analyses of Major Carbohydrate Products in Immobilized Cellulase Hydrolysate of Paper Cellulose
}

\author{
Cheanyeh Cheng ${ }^{\dagger}$ and Kuo-Chung Chang \\ Department of Chemistry, Chung Yuan Christian University, Chungli, Taiwan 32023, Republic of China
}

\begin{abstract}
A device with direct sampling, dilution, and sample loading has been utilized to couple a vertically hanging immobilized cellulase bioreactor with a high-performance liquid chromatography system to make a successful on-line analysis of the 3 major carbohydrate products: glucose, xylose, and cellobiose in the cellulase hydrolysate. The coupled analysis system for successive on-line monitoring of the enzymatic hydrolysis of paper cellulose was stable over a period of $96 \mathrm{~h}$. A comparative study involving 4 different quantification methods for the 3 carbohydrates was conducted. The internal standard calibration method with on-line dilution was observed to be the best procedure in terms of accuracy, precision, limit of detection, and systematic error reduction. With this method, the analysis for glucose had $99.9 \%$ accuracy, RSD below $2.4 \%$, and a $2.1 \mathrm{ppm}$ detection limit. Matrix matching was found important in the preparation of standard calibration curves with refractive index detection.
\end{abstract}

(Received September 22, 2006; Accepted November 14, 2006; Published March 10, 2007)

\section{Introduction}

Cellulose is a polymer of glucose and is the main structural material of plants. The use of purified cellulase or the whole cell of cellulase containing microorganisms to hydrolyze the cellulose in waste agricultural products or paper products to produce useful glucose is a mandatory and important subject in the scientific world. ${ }^{1}$ However, the analyses of monocarbohydrates such as glucose, galactose, mannose, xylose, and arabinose by traditional methods are very difficult due to the similarity in their structures. ${ }^{2}$ Modern detection techniques used to determine carbohydrates fall in 2 categories: high-performance liquid chromatography (HPLC) $)^{3-6}$ and enzyme electrode biosensors. ${ }^{7-10}$ When these methods were carried out in an off-line mode they usually posed the problems of sample transferring loss and contamination; they were timeconsuming and were incapable of providing immediate information for chemical or biochemical process evaluation to enable timely action. In contrast, on-line monitoring can quickly and accurately indicate not only substrate and product variations but also formation of and changes in intermediates. ${ }^{11-14}$ Accordingly, the on-line procedure displays a significant advantage in product quality control.

In order to analyze multi-components over a wide concentration range efficiently with on-line HPLC method, one needs sample dilution for high concentration analytes that can adjust the concentration of analytes within the linear range of the calibration curve. Most of the on-line dilution schemes ${ }^{15-18}$ described in the literature were complicated and used expensive equipment, while off-line dilution procedures often exhibited

$\uparrow$ To whom correspondence should be addressed.

E-mail: chengce@cycu.edu.tw sample loss and tedious procedures. It would be wise to simplify the on-line dilution scheme in a more convenient and economical way.

In this paper, a simple specific designed device was developed that can couple the HPLC analysis system to an immobilized cellulase bioreactor system. ${ }^{19}$ The specific designed device was operated manually; however, it can easily handle the sampling, dilution, and loading steps on-line. Thus, the concentration of the major carbohydrate products in cellulase hydrolysate can be on-line analyzed simultaneously. By using a refractive index (RI) detector, 4 kinds of quantification methods were compared to elucidate the suitability of the internal standard calibration method $^{20}$ with on-line dilution procedure for our on-line HPLC analysis system.

\section{Experimental}

Chemicals and materials

The cellulase complex (EC 3.2.1.4) purified form Trichoderma reesei and the reagent grade cellobiose were purchased from Sigma (USA). The reagent grade D-glucose, D-xylose, Dgalactose, D-arabinose, D-mannose, xylitol, D-lactic acid, and $\mathrm{CaCl}_{2}$ were all obtained from Merck (Germany). The sodium alginate was purchased from Lancaster (England). The reagent grade $\mathrm{NaOH}$ and $\mathrm{H}_{2} \mathrm{SO}_{4}$ were obtained from Showa Chemical Co. (Japan). Waste copy paper of A4 size was collected in the laboratory. Water was prepared from the tap water by reverse osmosis and distillation once. Membrane filter of $0.2 \mu \mathrm{m}$ pore size and $25 \mathrm{~mm}$ diameter was purchased from Advantic MFS, Inc. (USA). The helium gas was supplied by San-Yin Co. (Taiwan).

\section{Equipment}

The HPLC system consists of a dual piston pump (Shimadzu, 
LC-9A, Japan), an injection valve with a $20 \mu \mathrm{L}$ sampling loop (Rheodyne 7125, USA), a column oven (Shimadzu CTO-6A), a refractive index (RI) detector (Shimadzu RID-6A), and a personal computer (Pentium 586-166, Taiwan), equipped with chromatographic data processing software (SISC, Taiwan). The analytical column used for the HPLC system was the $\mathrm{H}^{+}$ionexchange column (Rezex ROA organic acid, $300 \times 7.8 \mathrm{~mm}$ i.d., Phenomenex, USA). The analytical column was protected with a guard column. The enzymatic hydrolysis reaction was performed with an automatically controlled fermentation system (Bio Top, BTF-A, Taiwan) and the $\mathrm{pH}$ electrode was obtained from Mettler (InPro 30301225, Switzerland).

The HPLC analysis system was coupled to the automatic controlled reaction system through a specific designed sampling, dilution, and loading device that was connected to the injection valve with a syringe needle. The schematic diagram of the coupled HPLC analysis system for the successive on-line monitoring of the major carbohydrate products is shown in Fig. 1(A). Figure 1(B) shows the details of the specific designed device. The removable syringe membrane filter of $0.22 \mu \mathrm{m}$ pore size and $13 \mathrm{~mm}$ diameter (Chrom Tech, USA) attached to the needle part and the two Luer lock valves of the device together with the porous plug filter assures that a clear cellulase hydrolysate can be injected into the HPLC analysis system. The two two-way Luer lock valves on the device were used for controlling the flow of the sample fluid and the diluent (water), respectively. This specific designed device for sampling, dilution, and loading was operated manually.

Paper cellulose hydrolysis with vertically hanging immobilized cellulase reactor

One liter solution containing $2.5 \mathrm{~g}$ of pretreated paper fiber ${ }^{19}$ was sterilized and cooled down to the reaction temperature of $45^{\circ} \mathrm{C}$. The immobilized cellulase pellets were put into a net and hung vertically on a rack that was specifically designed to suit the inner diameter of the reactor. ${ }^{19}$ Then, the rack with vertically hanging immobilized cellulase pellets was put into the $1 \mathrm{~L}$ paper fiber solution. The $\mathrm{pH}$ of the paper fiber solution was adjusted to 4.0 by using either $\mathrm{H}_{2} \mathrm{SO}_{4}$ or $\mathrm{NaOH}$. Then, the solution was agitated at a rate of $150 \mathrm{rpm}$ to begin the paper cellulose hydrolysis. The reaction period was 4 days. ${ }^{19}$

\section{Volume correction for the specific designed device}

Distilled water was drawn to the 1 or $2 \mathrm{~mL}$ mark on the syringe of the specific designed device. Then, water was injected into an empty and already weighed vial. The total weight of the vial and the water was recorded. The weight of the water drawn was obtained by the subtraction of the weight of the empty vial from the total weight. The procedure was repeated 5 times. The temperature was recorded for finding the correct water density. Finally, the average weight of the water drawn with the device was divided by the water density ${ }^{20}$ at the recorded temperature to obtain the correct volume.

\section{Preparation of standard calibration curves}

The 3 major carbohydrate products (viz. glucose, xylose, and cellobiose) in the immobilized cellulase hydrolysate were quantitatively determined by 4 different calibration methods, including 2 internal standard calibration curves with either online or off-line one-fold dilution of the standard solutions and 2 external standard calibration curves with either on-line or offline one-fold dilution of the standard solutions. In the preparation of the 2 internal standard calibration curves with either on-line dilution or off-line dilution, the internal standard used was xylitol. In order to match the matrix of the cellulase

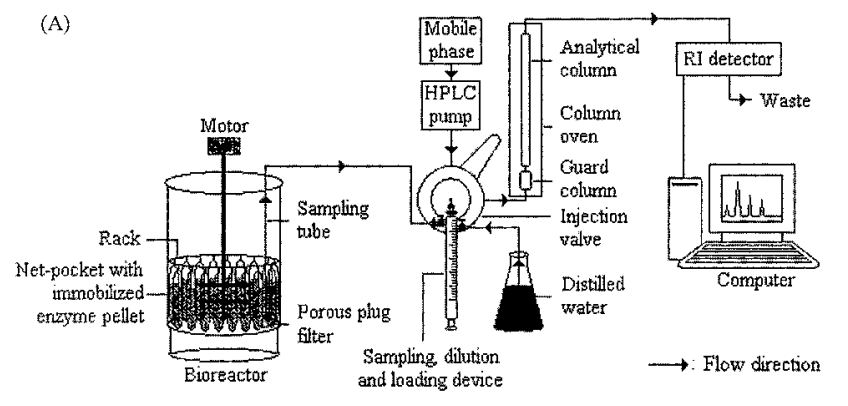

(B)

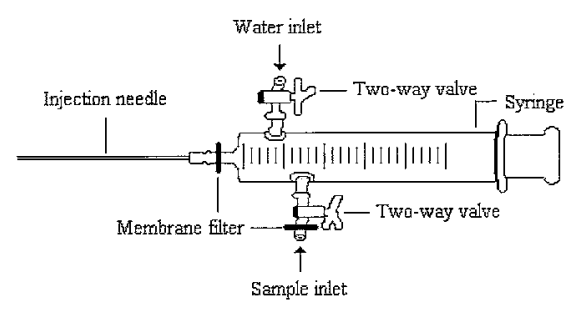

Fig. 1 (A) Schematic diagram of the coupled HPLC analysis system and (B) the enlarged specific designed device with the detailed features.

hydrolysate for the preparation of standard calibration curves, we hydrolyzed $2.5 \mathrm{~g}$ of paper cellulose with or without $1.0 \mathrm{~g}$ of internal standard in exactly the same way as described previously in the Paper cellulose hydrolysis section except that no cellulase was immobilized in the calcium alginate pellets.

The flow chart in Fig. 2(A) shows the procedures used to prepare the internal standard calibration curves with on-line dilution. A $2 \mathrm{~mL}$ matrix including the internal standard at 1000 ppm was first drawn from the bioreactor with the specific designed device (step I). One milliliter of the drawn matrix was injected out of the device for off-line dilution (step II). One milliliter of the matrix left in the device was used for one-fold on-line dilution with a $1 \mathrm{~mL}$ standard carbohydrate solution that was prepared with pure water at a specific concentration (step III). The one-fold diluted standard carbohydrate solution including the internal standard was then on-line injected and analyzed by HPLC (step IV). The data were collected and the internal standard calibration curves with one-fold on-line dilution were prepared by the least-squares method (step V).

The flow chart in Fig. 2(B) shows the procedures used to prepare the internal standard calibration curves with off-line dilution. A $2 \mathrm{~mL}$ matrix including the internal standard at 1000 ppm was first drawn from the bioreactor with the specific designed device (step I). One milliliter of the matrix was injected out of the device and collected into a beaker (step II). Then $0.5 \mathrm{~mL}$ of the $1 \mathrm{~mL}$ matrix from step II was taken out for dilution (step III). The $0.5 \mathrm{~mL}$ matrix was one-fold off-line diluted with another $0.5 \mathrm{~mL}$ standard carbohydrate solution that was prepared with pure water at a specific concentration (step IV). The one-fold diluted standard carbohydrate solution including the internal standard was off-line injected and analyzed by HPLC (step V). The data were collected and the internal standard calibration curves with one-fold off-line dilution were prepared by the least-squares method (step VI).

The procedures used to prepare the external standard calibration curves with either on-line dilution or off-line dilution are similar to the flow chart in Figs. 2(A) and (B), respectively, except that paper cellulose matrix not containing internal standard xylitol was put in the bioreactor and used for step I. Instead, xylitol was prepared as a standard carbohydrate with 

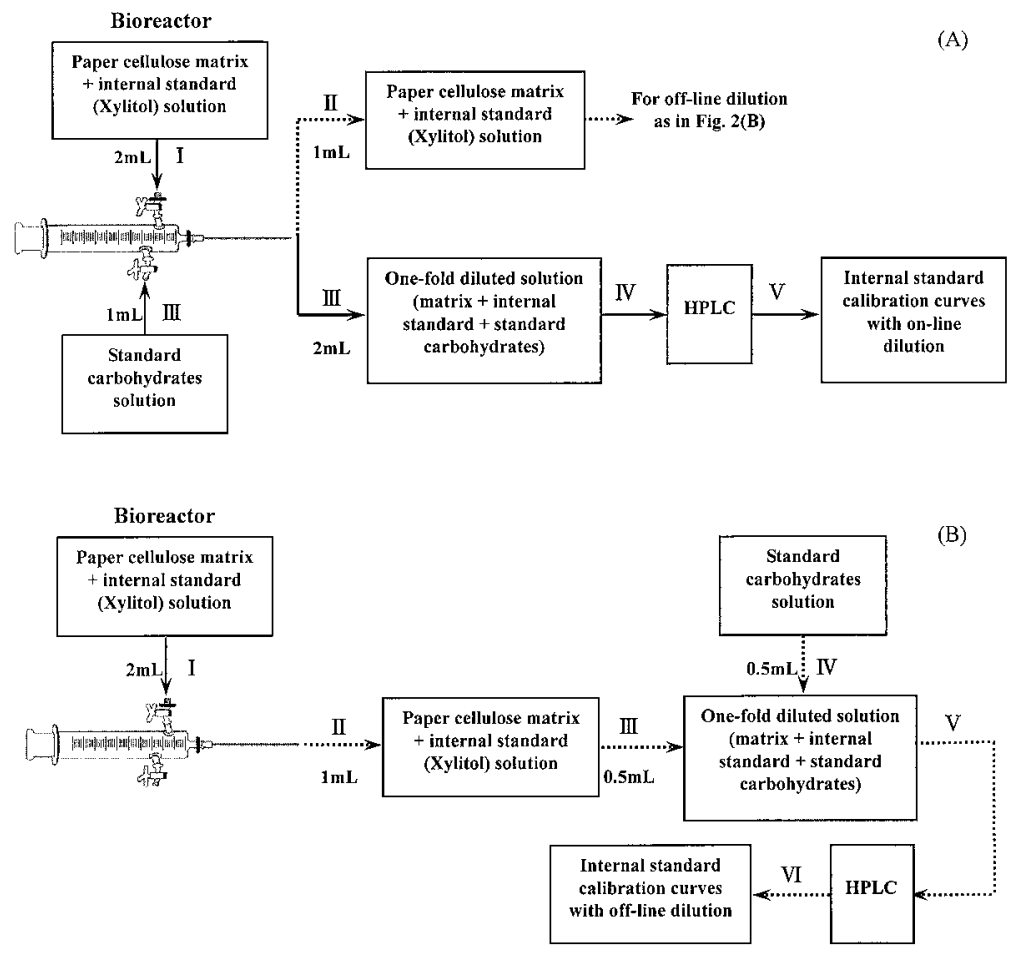

Fig. 2 Two flow charts for the procedures to prepare the standard calibration curves with one-fold dilution: (A) internal standard calibration curves with on-line dilution; (B) internal standard calibration curves with off-line dilution.

glucose, xylose, and cellobiose and used for step III in Fig. 2(A) or step IV in Fig. 2(B). The concentration ranges of the internal standard calibration curve prepared by either on-line dilution procedure or off-line dilution procedure were $0-1000 \mathrm{ppm}$ for glucose, 0 - $500 \mathrm{ppm}$ for xylose, and 0 - $500 \mathrm{ppm}$ for cellobiose. The concentration ranges of the external standard calibration curves for glucose, xylose, cellobiose, and xylitol were all 0 $1000 \mathrm{ppm}$.

Precision and accuracy of the coupled HPLC analysis system

The precision of the coupled HPLC analysis for the successive monitoring of carbohydrate products in the immobilized cellulase hydrolysate was estimated from the relative standard deviation (RSD) of the determined carbohydrate concentrations over a long reaction period at certain time intervals and was referred to those RSD values where a near steady state is obtained over the final reaction period.

The accuracy of the coupled HPLC analysis was estimated by the spike experiments, during which the standard solution containing a fixed amount of carbohydrate standards was added to the final reaction solution containing a predetermined amount of reaction products. The spiked reaction solution was analyzed exactly in the same way as described previously in the HPLC analysis section. Then the percent recovery of the added standards was calculated. The percent recovery of the standard reflects the analysis accuracy. The equation used to calculate the accuracy of the coupled HPLC analysis was the following:

$$
\text { Accuracy }=\left\{1-\left[\frac{\left|\left(\frac{C_{\mathrm{r}}+C_{\mathrm{s}}}{2}\right)-C_{\mathrm{t}}\right|}{\left(\frac{C_{\mathrm{r}}+C_{\mathrm{s}}}{2}\right)}\right]\right\} \times 100 \%
$$

Here $C_{\mathrm{r}}$ is the concentration of the specific carbohydrate in the final immobilized cellulase hydrolysate at the reaction time of $96 \mathrm{~h}, C_{\mathrm{s}}$ is the concentration of the added standard, and $C_{\mathrm{t}}$ is the total concentration of the specific carbohydrate in the immobilized cellulase hydrolysate after the standard addition.

\section{Successive on-line HPLC analysis of carbohydrate products}

The successive on-line analysis was based on the internal standard calibration curve method with on-line dilution procedure that was thought as the best analysis method; this was proved to be true in this paper. Cellulase hydrolysate $0.5 \mathrm{~mL}$ containing the internal standard xylitol was drawn directly out of the reactor and into the specific designed device during the reaction period at certain time interval, then, on-line diluted one-fold within the device. The diluted sample was subsequently loaded into the sampling loop of the injection valve and analyzed by HPLC. During the 4-day reaction period, the sampling time was $4 \mathrm{~h}$ initially, then every $8 \mathrm{~h}$ during the first 2 days, then every $12 \mathrm{~h}$ during the last 2 days. The experimental conditions for the successive on-line analysis of the paper cellulose hydrolysis at different time intervals were as follows: analytical column, Rezex ROA-organic acid; column temperature, $40^{\circ} \mathrm{C}$; mobile phase, $0.01 \mathrm{M} \mathrm{H}_{2} \mathrm{SO}_{4}$; flow rate of mobile phase, $0.6 \mathrm{~mL} \mathrm{~min}^{-1}$; detector, RI. After sample injection, the device was on-line washed with $3 \mathrm{~mL}$ distilled water 2 to 3 times to remove sample residues prior to the next injection.

\section{Results and Discussion}

Matrix effect on the standard calibration curve

Since the detector used for the coupled HPLC analysis system was a refractive index (RI) detector that is very sensitive to the 
Table 1 Limit of detection of the coupled HPLC analysis system for carbohydrate products and internal standard

\begin{tabular}{ccccc}
\hline \multirow{2}{*}{ Calibration method } & \multicolumn{5}{c}{ Limit of detection, ppm } \\
\cline { 2 - 6 } & Cellobiose & Glucose & Xylose & Xylitol \\
\hline $\begin{array}{c}\text { External standard calibration } \\
\text { curve with on-line dilution }\end{array}$ & 2.5 & 2.7 & 1.2 & 1.7 \\
$\begin{array}{c}\text { External standard calibration } \\
\text { curve with off-line dilution }\end{array}$ & 2.5 & 2.8 & 1.2 & 1.2 \\
$\begin{array}{c}\text { Internal standard calibration } \\
\text { curve with on-line dilution }\end{array}$ & 2.6 & 2.1 & 1.3 & \\
$\begin{array}{c}\text { Internal standard calibration } \\
\text { curve with off-line dilution }\end{array}$ & 2.7 & 2.3 & 1.3 & \\
\hline
\end{tabular}

Table 2 Percent recovery of the coupled HPLC analysis system for carbohydrate products and internal standard

\begin{tabular}{ccccc}
\hline \multirow{2}{*}{ Quantification method } & \multicolumn{5}{c}{ Recovery, \% } \\
\cline { 2 - 5 } & Cellobiose & Glucose & Xylose & Xylitol \\
\hline $\begin{array}{c}\text { External standard calibration } \\
\text { curve with on-line dilution }\end{array}$ & 97.7 & 99.2 & 99.6 & 98.5 \\
$\begin{array}{c}\text { External standard calibration } \\
\text { curve with off-line dilution }\end{array}$ & 98.9 & 99.2 & 99.5 & 99.4 \\
$\begin{array}{c}\text { Internal standard calibration } \\
\text { curve with on-line dilution }\end{array}$ & 98.7 & 99.9 & 99.6 & \\
$\begin{array}{c}\text { Internal standard calibration } \\
\text { curve with off-line dilution }\end{array}$ & 98.4 & 99.9 & 99.5 & \\
\hline
\end{tabular}

matrix concentration of the measured sample, differences in the extent of sample dilution would greatly affect the detection intensity of the analyte in the sample. The matrix effect was shown by the linearity of the four kinds of standard calibration curves. The standard calibration curves for cellobiose, glucose, xylose, and xylitol prepared by successive one-fold dilution from the largest concentration of the standard solution including the reaction matrix showed poor linearity (a curve) and their linear correlation coefficients $\left(r^{2}\right)$ were all about 0.982 .

As all the standard solutions at different concentrations were diluted individually and only one-fold, the linearity of all the standard calibration curves was greatly improved. The corresponding linear correlation coefficients $\left(r^{2}\right)$ for the 8 linear external standard calibration curves with either on-line dilution or off-line dilution of the 3 major carbohydrate products and the internal standard were from 0.9997 to 1 . The 3 linear internal standard calibration curves prepared with on-line dilution for the 3 carbohydrate products showed excellent linearity, with their corresponding linear correlation coefficients $\left(r^{2}\right)$ all over 0.9999 . The 3 linear internal standard calibration curves prepared with off-line dilution procedure also had excellent linearity, with their linear correlation coefficients $\left(r^{2}\right)$ all over 0.9997 .

\section{Detection limit and accuracy of the quantification method}

The limit of detection (LOD) and the analysis accuracy of the above-mentioned 4 kinds of quantification methods are one of the criteria used for determining which one of the 4 quantification methods should be most suitable for the analysis of the carbohydrate products during the hydrolysis course of time. Table 1 gives the results of the LOD for cellobiose, glucose, xylose, and xylitol using 3 times of the standard deviation of the response ${ }^{21}$ over the blank signal for the

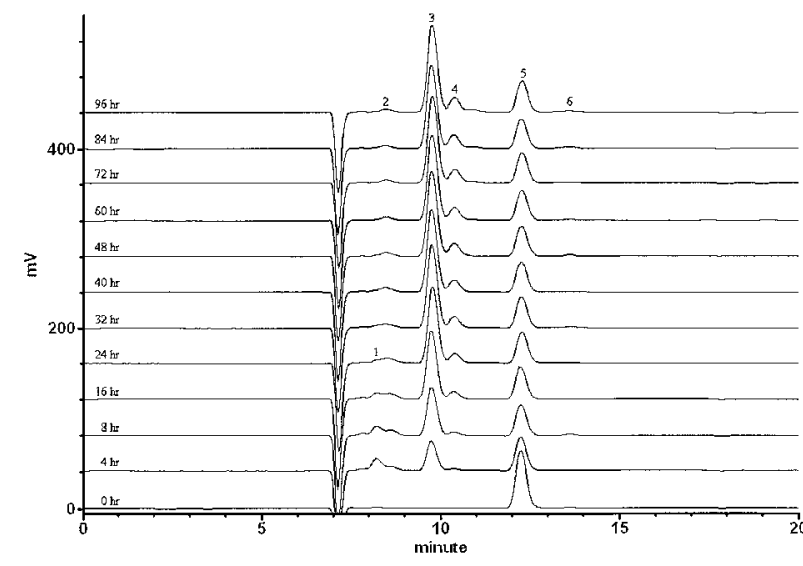

Fig. 3 Chromatograms exhibiting the successive on-line monitoring of the paper cellulose hydrolysis by the coupled HPLC analysis system with the internal standard calibration and on-line dilution method. Analytical column, Rezex ROA-organic acid; column temperature, $40^{\circ} \mathrm{C}$; mobile phase, $0.01 \mathrm{M} \mathrm{H}_{2} \mathrm{SO}_{4}$; flow rate, $0.6 \mathrm{~mL} \mathrm{~min}^{-1}$; detector, RI. Peak: 1, cellobiose; 2 , hemicellulose and pectin; 3, glucose; 4, xylose; 5, xylitol (internal standard); 6, lactic acid.

corresponding standard calibration curve created with concentrations below $25 \mathrm{ppm}$. In reference to the representative hydrolysis product glucose, the smallest LOD was $2.1 \mathrm{ppm}$ for the internal standard calibration method and on-line dilution procedure. On average, the LODs for glucose were smaller for the internal standard calibration method than for the external standard calibration method; the LODs for cellobiose and xylose were about the same for the internal standard calibration method and the external standard calibration method.

As shown in Table 2, the accuracy data for the 2 carbohydrate products, glucose and xylose, in terms of the percent recovery from the spike experiments were all over $99.2 \%$ for the 4 quantification methods. The product recovery of glucose from the quantification method using internal standard with either online or off-line dilution procedure can be as high as $99.9 \%$. The comparison of the accuracy data for cellobiose exhibited a recovery range from 97.7 to $98.9 \%$ for the 4 quantification methods. The reduced accuracy for cellobiose was due to the peak interference present in the immobilized cellulase hydrolysate. Overall, the recoveries for the quantification methods using internal standard calibration were better than those employing external standard calibration by the transferring errors of solution. For the 2 quantification methods using internal standard calibration, the recoveries obtained for both the on-line and off-line dilution procedures were similar with regard to the 3 carbohydrate products.

\section{Monitoring of carbohydrate products with the coupled HPLC} analysis system

The carbohydrate production time line for paper cellulose hydrolysis by the immobilized cellulase was successively monitored on-line at certain time intervals. The HPLC chromatograms that were taken at certain time intervals from 0 $\mathrm{h}$ to the final time $(96 \mathrm{~h})$ with on-line direct sampling and dilution procedures are shown in Fig. 3. The chromatograms illustrate the rapid accumulation of cellobiose during the initial $4 \mathrm{~h}$ reaction period; the material then gradually disappears during the following $92 \mathrm{~h}$ of the run. Glucose and xylose steadily accumulate from the beginning of the hydrolysis run 
Table 3 Quantification results by external standard calibration curve with (A) off-line dilution procedure and (B) on-line dilution procedure

\begin{tabular}{|c|c|c|c|c|c|c|c|c|c|}
\hline \multirow{2}{*}{\multicolumn{2}{|c|}{$\begin{array}{c}\text { Reaction } \\
\text { time/h }\end{array}$}} & \multicolumn{2}{|c|}{ Cellobiose } & \multicolumn{2}{|c|}{ Glucose } & \multicolumn{2}{|c|}{ Xylose } & \multicolumn{2}{|c|}{ Xylitol } \\
\hline & & $\begin{array}{c}\text { Conc., } \\
\text { ppm }\end{array}$ & $\begin{array}{c}\text { RSD, } \\
\%\end{array}$ & $\begin{array}{c}\text { Conc., } \\
\text { ppm }\end{array}$ & $\begin{array}{c}\text { RSD, } \\
\%\end{array}$ & $\begin{array}{c}\text { Conc., } \\
\text { ppm }\end{array}$ & $\begin{array}{c}\mathrm{RSD}, \\
\%\end{array}$ & $\begin{array}{c}\text { Conc., } \\
\text { ppm }\end{array}$ & $\begin{array}{c}\mathrm{RSD}, \\
\%\end{array}$ \\
\hline \multirow[t]{12}{*}{ (A) } & 0 & 3.9 & 12.5 & 13.0 & 17.7 & 0.0 & 0.0 & 498.7 & 1.1 \\
\hline & 4 & 140.8 & 1.6 & 448.1 & 2.0 & 56.8 & 12.0 & 498.0 & 1.3 \\
\hline & 8 & 121.0 & 3.4 & 773.3 & 1.0 & 111.3 & 2.1 & 497.4 & 1.3 \\
\hline & 16 & 76.1 & 6.3 & 1034.4 & 1.1 & 164.1 & 3.7 & 485.0 & 1.4 \\
\hline & 24 & 49.2 & 7.2 & 1298.8 & 0.6 & 184.5 & 2.5 & 487.8 & 0.8 \\
\hline & 32 & 31.5 & 6.3 & 1337.8 & 1.2 & 213.0 & 5.5 & 508.6 & 1.6 \\
\hline & 43 & 21.4 & 9.8 & 1371.9 & 0.7 & 231.6 & 2.8 & 485.5 & 1.1 \\
\hline & 48 & 13.5 & 8.0 & 1497.6 & 1.0 & 240.2 & 1.5 & 505.6 & 1.2 \\
\hline & 60 & 10.2 & 9.5 & 1523.6 & 1.3 & 245.8 & 5.0 & 491.3 & 2.0 \\
\hline & 72 & 7.1 & 15.2 & 1535.8 & 1.7 & 251.7 & 1.9 & 495.9 & 2.0 \\
\hline & 84 & 4.5 & 21.7 & 1531.7 & 1.6 & 247.1 & 2.7 & 482.6 & 1.7 \\
\hline & 96 & 3.9 & 23.6 & 1537.2 & 1.2 & 255.7 & 2.8 & 485.4 & 1.1 \\
\hline \multirow[t]{12}{*}{ (B) } & 0 & 4.1 & 10.6 & 13.0 & 11.3 & 0.0 & 0.0 & 463.7 & 0.9 \\
\hline & 4 & 155.2 & 4.1 & 459.4 & 1.1 & 56.2 & 4.2 & 529.5 & 1.4 \\
\hline & 8 & 158.5 & 0.9 & 808.4 & 1.3 & 110.5 & 2.8 & 526.0 & 0.9 \\
\hline & 16 & 68.7 & 3.5 & 1057.0 & 1.0 & 147.9 & 2.2 & 483.1 & 1.4 \\
\hline & 24 & 59.3 & 3.5 & 1344.7 & 1.9 & 198.4 & 1.6 & 532.5 & 2.1 \\
\hline & 32 & 41.7 & 5.4 & 1362.4 & 0.7 & 216.4 & 3.8 & 540.3 & 1.0 \\
\hline & 43 & 19.8 & 9.2 & 1413.7 & 0.7 & 219.9 & 1.6 & 504.4 & 0.6 \\
\hline & 48 & 14.2 & 5.8 & 1507.6 & 1.0 & 237.0 & 3.2 & 516.2 & 0.5 \\
\hline & 60 & 10.6 & 17.9 & 1546.6 & 0.7 & 243.7 & 1.6 & 519.3 & 0.6 \\
\hline & 72 & 9.0 & 8.4 & 1512.3 & 1.4 & 252.8 & 2.2 & 511.2 & 1.4 \\
\hline & 84 & 7.2 & 12.2 & 1525.7 & 0.6 & 259.5 & 1.0 & 511.7 & 0.7 \\
\hline & 96 & 5.5 & 13.3 & 1547.2 & 0.8 & 262.7 & 0.7 & 513.7 & 0.6 \\
\hline
\end{tabular}

and with no obvious concentration change observed for the internal standard xylitol. The initial accumulation of cellobiose demonstrates that the enzyme activity of $\beta$-glucosidase in the cellulase complex is not compatible with the enzyme activities for exoglucanase and endoglucanase, respectively.

The simultaneous quantitative determination of the 3 major hydrolysis products with the coupled HPLC analysis system and the 4 kinds of quantification methods was shown by Tables 3 and 4. The maximum attainable concentrations for the representative carbohydrate product (glucose) evaluated by the 4 quantification methods, were 1537.2 $\pm 18.2,1547.2 \pm 13.0$, $1620.6 \pm 31.7$, and $1616.5 \pm 20.4 \mathrm{ppm}$. Since the concentration change of internal standard xylitol was quite steady along the time duration of the immobilized cellulase hydrolysis, the application of the coupled HPLC on-line analysis system with the specific designed device for the successive monitoring of carbohydrate products in the hydrolysate was satisfactory. Since each of the hydrolysate samples was analyzed 5 times and the analysis time for each analysis was about $20 \mathrm{~min}$, the total analysis time was about $100 \mathrm{~min}$; such a delay made the analysis far away from the real time mode. This drawback may be improved by reducing the number of measurements for each sample to 2 .

Comparison of the quantification method for the coupled HPLC analysis system

The results shown in Tables 3 and 4 indicate that the amounts of the 3 carbohydrate products determined by the coupled HPLC analysis system employing the internal standard calibration methods were greater than the results obtained using the external standard calibration methods. By using glucose as an example, we found that the difference between the 2 average
Table 4 Quantification results by internal standard calibration curve with (A) off-line dilution procedure and (B) on-line dilution procedure

\begin{tabular}{|c|c|c|c|c|c|c|c|}
\hline \multirow{2}{*}{\multicolumn{2}{|c|}{$\begin{array}{c}\text { Reaction } \\
\text { time/h }\end{array}$}} & \multicolumn{2}{|c|}{ Cellobiose } & \multicolumn{2}{|c|}{ Glucose } & \multicolumn{2}{|c|}{ Xylose } \\
\hline & & $\begin{array}{c}\text { Conc., } \\
\text { ppm }\end{array}$ & $\begin{array}{c}\mathrm{RSD}, \\
\%\end{array}$ & $\begin{array}{c}\text { Conc., } \\
\text { ppm }\end{array}$ & $\begin{array}{c}\mathrm{RSD}, \\
\%\end{array}$ & $\begin{array}{c}\text { Conc., } \\
\text { ppm }\end{array}$ & $\begin{array}{c}\mathrm{RSD}, \\
\%\end{array}$ \\
\hline \multirow[t]{12}{*}{ (A) } & 0 & 5.0 & 21.5 & 13.4 & 22.5 & 0.0 & 0.0 \\
\hline & 4 & 151.9 & 2.7 & 502.3 & 2.7 & 61.5 & 11.1 \\
\hline & 8 & 130.9 & 4.0 & 869.7 & 2.0 & 116.8 & 2.3 \\
\hline & 16 & 85.0 & 6.8 & 1193.6 & 2.1 & 174.7 & 3.9 \\
\hline & 24 & 55.3 & 7.8 & 1376.0 & 1.2 & 194.9 & 2.5 \\
\hline & 32 & 34.7 & 8.3 & 1443.4 & 2.5 & 224.5 & 2.8 \\
\hline & 43 & 25.1 & 11.9 & 1559.4 & 1.5 & 244.8 & 3.0 \\
\hline & 48 & 15.9 & 14.0 & 1570.7 & 1.8 & 243.7 & 2.0 \\
\hline & 60 & 12.7 & 17.2 & 1600.1 & 3.0 & 256.4 & 5.6 \\
\hline & 72 & 9.3 & 24.0 & 1611.8 & 3.3 & 260.1 & 3.2 \\
\hline & 84 & 6.7 & 32.7 & 1616.4 & 2.9 & 262.4 & 3.4 \\
\hline & 96 & 5.9 & 36.2 & 1620.6 & 2.0 & 269.8 & 3.1 \\
\hline \multirow[t]{12}{*}{ (B) } & 0 & 5.0 & 21.5 & 13.4 & 22.5 & 0.0 & 0.0 \\
\hline & 4 & 159.4 & 4.7 & 463.6 & 2.5 & 57.7 & 4.2 \\
\hline & 8 & 163.8 & 2.0 & 823.5 & 1.9 & 112.4 & 2.9 \\
\hline & 16 & 77.4 & 4.6 & 1173.3 & 2.2 & 163.0 & 2.8 \\
\hline & 24 & 61.0 & 5.5 & 1354.9 & 3.6 & 197.8 & 3.3 \\
\hline & 32 & 42.5 & 7.1 & 1452.4 & 1.6 & 212.5 & 4.0 \\
\hline & 43 & 21.8 & 12.5 & 1563.8 & 1.2 & 231.1 & 1.8 \\
\hline & 48 & 15.5 & 13.5 & 1567.2 & 1.3 & 243.3 & 3.2 \\
\hline & 60 & 11.6 & 23.6 & 1598.4 & 1.2 & 248.7 & 1.8 \\
\hline & 72 & 10.1 & 20.4 & 1607.7 & 2.4 & 262.0 & 2.9 \\
\hline & 84 & 8.2 & 25.7 & 1614.0 & 1.2 & 268.6 & 1.3 \\
\hline & 96 & 6.4 & 31.7 & 1616.5 & 1.3 & 270.8 & 1.0 \\
\hline
\end{tabular}

values of the last 5 data at about steady state in the reaction time line from the 2 standard calibration curves with off-line dilution procedure was about $4.9 \%$. Similarly, the difference between the 2 average values for the 2 calibration methods with on-line dilution procedure was about $4.5 \%$. Although the differences were not large, these results did indicate the existence of systematic error between the 2 standard calibration methods. The sources of the systematic error are probably due to sample transfer loss and to the use of different kinds of measurement apparatuses for the 2 calibration methods.

Tables 3 and 4 also show that the precision for glucose was generally satisfactory during the steady state time line beginning with the $48 \mathrm{~h}$ interval. The relative standard deviations (RSD) of glucose were less than $3.3 \%$ with the 4 quantification methods. On average, the RSD values of glucose determined by the internal standard calibration method and on-line dilution procedure were smaller than those determined by its off-line dilution procedure. Again, the very large RSD values exhibited with cellobiose were due to peak interference, as shown by the chromatograms in Fig. 3.

The advantage of using the internal standard calibration method for the coupled HPLC analysis system in successive online monitoring cellulose hydrolysis can also be proved by comparing the deviations between the dilution procedures for the 2 standard calibration methods with the statistical paired $t$ test. ${ }^{21}$ The results shown in Table 5 indicated that no significant difference at $95 \%$ confidence level of the measured data in the hydrolysis time course could be found for all the 3 carbohydrate products from the 2 dilution procedures of internal standard calibration method. However, a significant difference at $95 \%$ confidence level of the measured data in the hydrolysis time course was found for both glucose and xylitol with the 2 
Table 5 Statistical paired $t$-test comparison of the results between the on-line dilution procedure and the off-line dilution procedure for the external standard calibration method and the internal standard calibration method, respectively

\begin{tabular}{|c|c|c|c|c|c|c|}
\hline \multirow[b]{2}{*}{ Carbohydrate } & \multicolumn{3}{|c|}{ External standard calibration curve } & \multicolumn{3}{|c|}{ Internal standard calibration curve } \\
\hline & $t_{\text {table }}(95 \%)$ & $t_{\text {cal. }}$ & $\begin{array}{l}\text { Difference between on-line } \\
\text { and off-line dilution }\end{array}$ & $t_{\text {table }}(95 \%)$ & $t_{\text {cal. }}$ & $\begin{array}{l}\text { Difference between on-line } \\
\text { and off-line dilution }\end{array}$ \\
\hline Cellobiose & 2.209 & 1.765 & No & 2.209 & 1.259 & No \\
\hline Glucose & 2.209 & 2.783 & Yes & 2.209 & 2.156 & No \\
\hline Xylose & 2.209 & 0.109 & No & 2.209 & 1.790 & No \\
\hline Xylitol & 2.209 & 3.184 & Yes & & & \\
\hline
\end{tabular}

dilution procedures of the external standard calibration method. The statistical paired $t$-test showed that the use of internal standard had allowed the quantitative determination of the 3 carbohydrate products in the cellulase hydrolysate to give values in good agreement with each other by either on-line dilution procedure or off-line dilution procedure.

\section{Conclusions}

In the present study, a simple specific designed device was utilized to combine an automatically controlled bioreactor system and the HPLC analytical system to perform the direct sampling, dilution, sample loading, and successive on-line analysis of major carbohydrate products in immobilized cellulase hydrolysate. The use of this device can simplify the most used on-line HPLC analysis system by replacing the peristaltic pump, eliminating unnecessary tubing and valves, thus reducing equipment cost. Four kinds of quantification method including the internal standard calibration method with either on-line or off-line dilution procedure and the external standard calibration method with either on-line or off-line dilution procedure were compared for the determination of the amount of glucose, cellobiose, and xylose at different reaction time intervals. The internal standard calibration method with on-line dilution procedure should be used as originally thought in terms of LOD, precision, accuracy, convenience, and the reduction of systematic error. Since no significant variation in response for the internal standard xylitol was observed during the $96 \mathrm{~h}$ hydrolysis period, the development of this new type online HPLC analysis system is successful.

\section{Acknowledgements}

The authors gratefully acknowledge the financial support from National Science Council under the grant number NSC 922113-M-033-015.

\section{References}

1. C. E. Cheng, "Development, Modeling, and Simulation of the Anaerobic Fermentation from Glucose to Acetic Acid by Clostridium Thermoaceticum", 1987, Ph. D. Dissertation, Rutgers State Univ., NJ.

2. C. K. Mathews, K. E. van Holde, and K. G. Ahern, "Biochemistry", 3rd ed., 2000, Allison Pearson, Inc., San Francisco, CA, 284.

3. M. I. Mora and J. M. Marioli, J. Liq. Chromatogr. Relat. Technol., 2001, 24, 711 .

4. P. Abreu, A. Pereira, and A. Relva, Carbohydr. Polym., 2001, 45, 155.

5. M. Torimura, K. Kano, T. Ikeda, M. Goto, and T. Ueda, J. Chromatogr., A, 1997, 790, 1.

6. T. A. Buttler, K. A. J. Johansson, L. G. O. Gorton, and G. A. Marko-Varga, Anal. Chem., 1993, 65, 2628.

7. A. Maines, D. Ashworth, and P. Vasgama, Food Technol. Biotechnol., 1996, 34, 31.

8. A. Haouz and S. Stieg, Enzyme Microb. Technol., 2002, 30, 129.

9. V. Rajendran and J. Irudayaraj, J. Dairy Sci., 2002, 85, 1357.

10. M. M. Rhemrev-Boom, M. A. Jonker, K. Venema, G. Jobst, R. Tissen, and J. Korf, Analyst, 2001, 126, 1073.

11. Y. Nanjo, T. Yano, R. Hayashi, and T. Yao, Anal. Sci., 2006, 22, 1135.

12. O.-J. Sohn, K.-A. Han, and J. I. Rhee, Talanta, 2005, 65, 185.

13. J. I. Rhee and O.-J. Sohn, Anal. Chim. Acta, 2003, 499, 71.

14. E. F. Umoh, A. B. V. Putten, and K. Schügerl, J. Chem. Technol. Biotechnol., 1996, 67, 276.

15. K. Dai, A. G. Vlessidis, and N. P. Evmiridis, Talanta, 2003, 59, 55.

16. D. G. Themelis, A. Economou, A. Tsiomlektsis, and P. D. Tzanavaras, Anal. Biochem., 2004, 330, 193.

17. J. F. van Staden, M. G. Mashamba, and R. I. Stefan, Talanta, 2002, 58, 1089.

18. J. N. Oquendo and J. A. Leone, Anal. Chem., 1989, 61, 1791.

19. C.-C. Wu and C. Cheng, J. Chin. Chem. Soc., 2005, 52, 85.

20. D. C. Harris, "Quantitative Chemical Analysis", 7th ed., 2007, W. H. Freeman and Company, New York, 32.

21. J. N. Miller and J. C. Miller, "Statistics and Chemometrics for Analytical Chemistry", 4th ed., 2000, Pearson Education Limited, England, 121. 